Alex J. Ryan

\title{
A Framework for Systemic Design
}

\begin{abstract}
As designers move upstream from traditional product and service design to engage with challenges characterised by complexity, uniqueness, value conflict, and ambiguity over objectives, they have increasingly integrated systems approaches into their practice. This synthesis of systems thinking with design thinking is forming a distinct new field of systemic design. This paper presents a framework for systemic design as a mindset, methodology, and set of methods that together enable teams to learn, innovate, and adapt to a complex and dynamic environment. We suggest that a systemic design mindset is inquiring, open, integrative, collaborative, and centred. We propose a systemic design methodology composed of six main activities: framing, formulating, generating, reflecting, inquiring, and facilitating. We view systemic design methods as a flexible and open-ended set of procedures for facilitating group collaboration that are both systemic and designerly.
\end{abstract}

Keywords: systemic design, strategic design, design thinking, systems thinking, methodology.

\section{Introduction}

The purpose of this paper is to present a general framework for systemic design, in order to facilitate design applications to business, organisational, governmental, and societal challenges. By making the framework accessible to both public service and citizen designers, it is hoped that small groups can make big changes towards a better world.

The first section of this paper briefly introduces the two major interdisciplinary fields that systemic design integrates: systems thinking and design thinking. In the next section, we explain what we mean by systemic design and when it applies. Then, we present a framework for systemic design consisting of three levels: mindset, methodology, and, methods. The mindset of the systemic designer is characterised as a set of values and habits. Next, the logic for a systemic design project is outlined and developed as a flexible methodology for developing deeper understanding and constructing novel interventions. Finally, the uses and abuses of methods are examined. Any systemic design project proceeds at all three levels simultaneously, with the levels mutually reinforcing and reciprocally influencing one another.

\section{Systems Thinking and Design Thinking}

The two fields underpinning systemic design are systems thinking and design thinking. Both benefit from a rich and diverse tradition of interdisciplinary praxis. In systems thinking, the original mid-twentieth century closely-knit couple of general system theory (von Bertalanffy, 1956) and cybernetics (Wiener, 1948) have given birth to a large family of systems approaches, including systemic therapy, systems analysis, systems engineering, synergetics, living systems theory, system dynamics, second order cybernetics, soft systems methodology, nonlinear dynamical systems, complex systems, critical systems thinking, and total systems intervention (see for example (Midgely, 2003)). These variants define 'system' differently, adopt significantly different philosophical positions, employ different systems methods, and cast the systems thinker in different roles. If viewed from an evolutionary perspective, this pattern of growth and differentiation of the field of systems thinking can be seen as producing multiple concurrent systems approaches that are adapted to different niche applications of the systems idea.

Design is more commonly differentiated by the substantive materials the designer gives form to: architectural design, engineering design, urban planning, industrial design, fashion design, graphic design, software design, interaction design, experience design, and 
organisational design, to name a few. The term design thinking is of more recent origin than these antecedents. It first appeared during the 1960s. Cross (2006) identified the London Conference on Design Methods in 1962 as a landmark event, which led to the founding of the Design Research Society and "...marked the launch of design methodology as a subject or field of enquiry, and the 'design methods movement'." This movement introduced the term design thinking in its modern sense of shifting attention away from the artifacts of design to the general process of designing (see for example (Archer, 1965; Jones, 1969)).

In the last decade, the workshop and edited book Managing as Designing (Boland \& Collopy, 2004), as well as the collaborations among Procter and Gamble, IDEO, the Rotman School, and IIT Institute of Design (Brown \& Katz, 2009; Martin, 2009), have generated widespread awareness of design thinking beyond the field of design, particularly its applications to business. While the term design thinking may have helped to initiate conversations about designing that transcend any single medium of design, there still exist many interpretations of design across and extending beyond the design professions.

A challenge this diversity in both fields creates is that terminology becomes massively overloaded. This makes clear communication within and between fields extremely difficult. Which systems thinking? Which design thinking? What is meant by a system? What is meant by design? Practitioners rarely have experience in more than a few different systems thinking / design thinking variants because of the years of study and practice needed to master even one. Because of this, a conversation between an engineering designer using systems analysis and an experience designer employing soft systems methodology is likely to end up lost in translation. Our engineering designer sees systems as tangible parts of the world that can be re-engineered, while our experience designer sees systems as a way of organising their thinking about a situation that is messy and problematic, but not composed of any physical systems. While both may be engaged in systemic design, they will have difficulty learning from one another as long as they continue to talk past one another.

A framework for systemic design that commits to a single variant of systems thinking and design thinking would simplify the task of developing a clear and consistent vocabulary. However, it would also be highly restrictive when faced with the rich and varied demands of practice. If the value of connecting systems thinking and design thinking is related to the diversity of each tradition, then a framework should be open to many different syntheses of systemics and design. To be useful beyond single niche applications, a systemic design framework should allow practitioners to select the variants of systems thinking and design thinking that fit their particular challenge. Therefore, rather than subscribing to one of the dominant schools of either systems thinking or design thinking, we will instead describe in general terms what these concepts imply for us. Our definitions are not authoritative. They merely communicate how the terms will be used in the context of this paper to permit diverse and sometimes conflicting variants of systems thinking and design thinking to be integrated within a flexible and practical framework.

By systems thinking, we mean a way of looking at, modelling, and intervening in the world as if it is composed of open, purposeful, complex wholes. Following François (1999), we use the term systemics to refer to the aggregate of continually evolving systems approaches. A key concept of systemics is interdependence: webs of reciprocal influence between parts of a greater whole and their environment. Interdependencies between system components and their environment give rise to emergence, self-organisation, learning, adaptation, evolution, power law statistics, chaos, complexity, and other "surprise-generating mechanisms" (Casti, 1997) that systems thinkers pay attention to.

The opposite of interdependence is independence. A collection of independent parts contains no feedback or communication between the parts. The aggregate behaviour is governed by the law of large numbers, which implies it is predictable to within three standard 
deviations of the mean. In contrast, a system composed of interdependent parts (which are open to exchanges of matter, energy, and information with their environment) behaves complexly, is capable of generating and locking in novelty, and produces extreme events that are orders of magnitude greater than the median event size. Averages do not tell us much about a complex system with interdependent parts.

An implication of interdependence is that actions have effects other than those intended. Since everyone always sees and acts locally, there is no reason to expect that an aggregation of incremental improvements will improve the greater whole. Systemics exposes an assumption we have organised our societies around. This is the assumption that knowledge and action are both furthered when we divide them into smaller pieces over and over again. It leads to - among other things - the separation between theory and practice, the fragmentation of knowledge, and the loss of meaning in work. Systemics presents an alternative approach to acting to improve complex situations that has dramatic consequences for the way we work together. Regardless of the variant of systems thinking employed, the systems thinker emphasises the importance of analysing in context (rather than analysing parts in isolation) and of synthesising information across disciplines, scales, and perspectives.

By design thinking, we mean a normative, user-centred, iterative approach to innovation that extends the application of design beyond the design of symbols, objects, and interactions. Following Schön (1987), we view designing as a synthetic and constructive process of making representations of new things to be brought to into being. A key concept of design is intentionality: the capacity of humans to meaningfully embed their values and ideas in artifacts. These artifacts are designed for people - for users and stakeholders. Design thinking humanises processes of change by beginning with empathy for those who will be most affected by the design.

An implication of design is that nothing in our world is purely natural. In the age of the Anthropocene, every system on Earth is entangled with intentional human action. Everything is touched by design. Therefore, everything can be redesigned. The idea of intentionality challenges us to look at everything in our world with new and critical eyes so that we might see its design flaws. Even more than this, it challenges us to move beyond mere criticism to get started on redesigning a better world today.

\section{Systemic Design as Integrating Systemics and Design}

When systemics and design are mixed, the result is a truly potent synthesis that we will call systemic design. Systemic design allows groups to appreciate situations from multiple scales and perspectives. It provides ways of deeply empathising with stakeholders, while working alongside them to collectively apprehend and construct a broader context within which to situate our challenges. Systemic design helps groups to challenge boundaries, construct shared frames of reference, visualise alternatives to prevailing paradigms, and align actions to improve messy situations. Systemic design is to us an approach to working together to act, reflect, and learn while doing.

The framework for systemic design introduced in this paper makes a number of presuppositions about the world, organisations, teams, and individuals. This framework assumes that:

- The world is perpetually changing;

- Change includes fundamentally unpredictable emergent novelty;

- All systemic design is provisional and open to redesign;

- All systemic design projects are entangled with social systems - there are no purely natural or technical systems; 
- Social systems and organisations are socially constructed and can be reconstructed;

- Small teams are capable of partially redesigning organisations and societies; and

- Without reframing that shifts the thinking of individuals within design teams, except by accident, redesign projects will be incremental rather than transformational.

These presuppositions differentiate our systemic design framework from approaches that assume a degree of stability and predictability in the world; attempt to produce complete and final plans; separate the design of social and technical systems; ascribe a mind-independent objective reality to social systems; or attempt to change behaviour without surfacing the patterns of thinking that guide action. Our framework can accommodate different mixtures of systemics and design, as long as they conform to these basic presuppositions.

Systemic design is not universally applicable to all challenges. Many important problems organisations face are routine problems, where stakeholders share common values, important variables can be quantified, and solutions from prior occurrences of the problem remain valid. There are still other problems that reside within the purview of a single department or within a single academic discipline. There are more efficient approaches to routine problem solving and problems requiring deep subject matter expertise than systemic design.

Systemic design as we define it here is intended for situations characterised by complexity, uniqueness, value conflict, and ambiguity over objectives. ${ }^{1}$ Systemic design can engage with value conflicts between stakeholders to develop broader, shared frames of reference and new ways of seeing existing challenges. New perspectives can unlock potential for substantial innovation and discontinuous improvement. Systemic design rapidly transitions creative breakthroughs into tangible actions to improve the situation, and sets processes in place to proactively adapt to a changing context. Systemic design helps a client to make substantive progress on their most complex challenges.

\section{Three Levels of Systemic Design}

Our framework conceives of systemic design as consisting of three mutually reinforcing levels: mindset, methodology, and method.

By method, we mean a set of procedures for facilitating group process that specifies how group members should work together to generate and externalise ideas.

By methodology, we mean a logic for selecting and combining methods in a coherent sequence to move between deepening understanding of the challenge and generating actions to improve the situation. Each school of systems and/or design practice tends to promote a signature methodology as a key point of differentiation. Despite this variance, a large number of innovation methodologies have been mapped by VanPatter and Pastor (2013) into a generic cycle with four main sequential activities: Discover and orient; Define and conceptualise; Optimise and plan; and Execute and measure, shown in Figure 1. This cycle is based on the Osborn-Parnes creative problem solving process (Osborn, 1963), as also formulated in the Basadur Simplexity process (Basadur, Graen and Wakabayashi, 1990). Systems and/or design methodologies label, lump, and split these activities differently, but this schema is useful for comparing the relative weight of emphasis of alternative methodologies. 


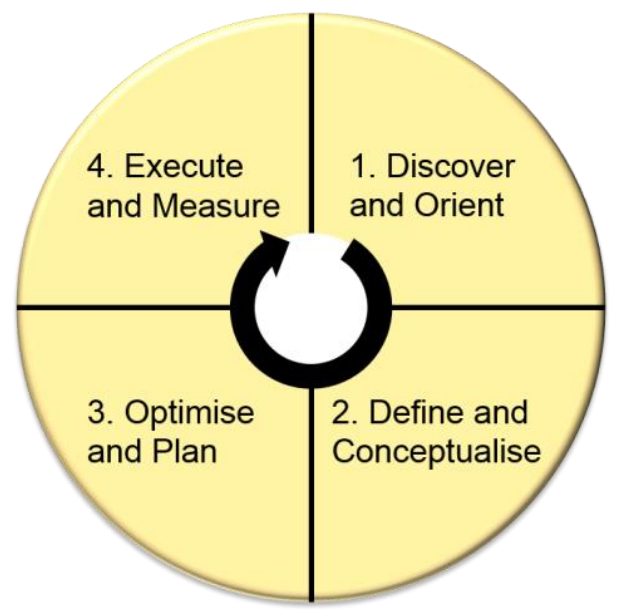

Figure 1. Cycle of continuous innovation.

By mindset, we mean the values and habits the systemic designer brings to the challenge, which guide judgement during the application of methodology and shape selection of methods. Methodology is meta to the level of method: it is about method, providing principles that justify the use of a particular method or methods (Checkland, 2000). Similarly, mindset is meta to the level of methodology: it justifies the choice of methodology and guides interpretation through the values the mindset promotes. These three levels are interrelated, as depicted in Figure 2. Each new systemic design experience creates opportunities for application and co-evolution of the practitioner's mindset, methodology, and methods.

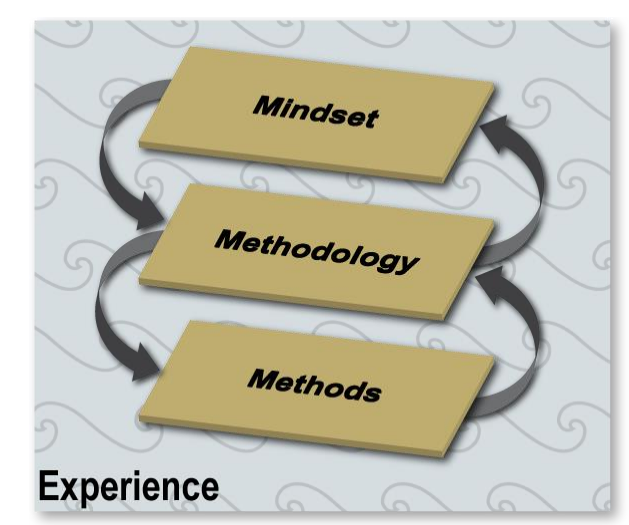

Figure 2. Three levels of systemic design.

\section{Systemic Design Mindset}

The systemic design mindset describes a set of values and habits that guide the interpretation of methodology and the application of methods. Values can be defined as "conceptions of the desirable that guide the way social actors (e.g. organisational leaders, policy-makers, individual persons) select actions, evaluate people and events, and explain their actions and evaluations" (Schwartz, 1999). Habits can be defined as routines of behavior acquired through previous repetition of a mental experience (Andrews, 1908). Both values and habits share the characteristics of being resistant to change and slow to change. The systemic design mindset cannot be taught directly. It is only through repeated systemic design experiences that individuals can, through reflection and behaviour modification, choose to enact new values and form new habits. 
In our judgement, the best systemic designers are inquiring, open, integrative, collaborative, and centred. Bruce Mau's "An Incomplete Manifesto for Growth" articulates a mindset we find consistent with systemic design. He captures (among others) the first four of our characteristics in the following abridged items (Mau, 1998):

Ask stupid questions. Assess the answer, not the question.

Allow events to change you. You have to be willing to grow. Growth is different from something that happens to you. You produce it. You live it. The prerequisites for growth: the openness to experience events and the willingness to be changed by them.

Organization $=$ Liberty. Real innovation in design, or any other field, happens in context. That context is usually some form of cooperatively managed enterprise.

Collaborate. The space between people working together is filled with conflict, friction, strife, exhilaration, delight, and vast creative potential.

The fifth characteristic - centred - is emphasised by Nelson (2012). For Nelson, centred design "...places designing and design in a larger systemic frame (including milieu, environment, metasystems etc.).... I also use the term to denote the process of designing that is constitutive of a wide variety of people (a social system) working in common with a shared purpose" (H. Nelson, personal communication, June 11, 2014). The five characteristics, along with their associated values and habits, are summarised below in Table 1.

Table 1. Five characteristics of a systemic design mindset.

\begin{tabular}{|lll|}
\hline Characteristic & Value & Habits \\
\hline Inquiring & Learning & Curious; observant; asks rather than assumes \\
\hline Open & Growth & $\begin{array}{l}\text { Defers judgement; seeks different experiences and } \\
\text { perspectives; willing to change one's mind }\end{array}$ \\
\hline Integrative & Accommodation & $\begin{array}{l}\text { Avoids binary trade-offs; seeks win-win games; utilises } \\
\text { tension between worldviews creatively }\end{array}$ \\
\hline Collaborative & Teamwork & $\begin{array}{l}\text { Listens actively; builds on others' ideas; grows social } \\
\text { cohesion; builds shared ownership and accountability }\end{array}$ \\
\hline Centred & Mindedness & $\begin{array}{l}\text { Reflective self-awareness; views challenges in a larger } \\
\text { context; mediates tensions between extremes }\end{array}$ \\
\hline
\end{tabular}

A theme that emerges across these five characteristics is a propensity for the systemic designer to seek out different perspectives and weave them together into an integrated tapestry of inquiry and action. The deliberate pursuit of diversity generates tensions that are both the creative engine of innovation and a potential source of escalating conflict and team disintegration. Cognitive tensions the systemic designer must mediate are listed in Table 2. 
Table 2. List of cognitive tensions that must be mediated in systemic design.

\begin{tabular}{|c|c|c|}
\hline \multicolumn{2}{|c|}{ Cognitive Tension } & \multirow{2}{*}{$\begin{array}{l}\text { How to Mediate the Tension } \\
\text { Systemic design is inquiry for action (Nelson, 2012). Deeper } \\
\text { understanding informs right action, while action stimulates new } \\
\text { understanding. Tension is mediated by controlling the tempo and } \\
\text { synchronising the team's iteration between inquiry and action. }\end{array}$} \\
\hline Inquiry & Action & \\
\hline Interiority & Exteriority & $\begin{array}{l}\text { Systemic design brings marginal perspectives to the centre of } \\
\text { organisations. Rather than homogenise the system, systemic design } \\
\text { diversifies the centres where design decisions are made. Tension } \\
\text { between interior and exterior (Deleuze \& Guattari, 2009) perspectives } \\
\text { is mediated by surfacing the dominant paradigm and then creating } \\
\text { space for alternative explanations to be heard and explored. }\end{array}$ \\
\hline Becoming & Being & $\begin{array}{l}\text { Systemic design maps situations dynamically to account for their } \\
\text { history, current state, and potential futures. Creating frames at } \\
\text { different points in time illuminates discontinuities between existing } \\
\text { patterns and emerging developments - between being and becoming } \\
\text { (Savitt, 2014). Tensions between legacy and potential frames are } \\
\text { mediated by relating them within the frame of the current state to } \\
\text { honour the past and build the future. }\end{array}$ \\
\hline Mind & World & $\begin{array}{l}\text { Systemic design surfaces and often reframes boundary judgments } \\
\text { (Ulrich, 1983). The systems maps we draw tell us at least as much } \\
\text { about our own frameworks and biases as they tell us about the } \\
\text { situation of interest. The tension between mind and world is mediated } \\
\text { by examining the drift between expectations derived from mental } \\
\text { models and the flow of actual events. Dissonances between map and } \\
\text { territory (Korzybski, 1933), mind and world, present opportunities for } \\
\text { critical reflection and team learning. }\end{array}$ \\
\hline Top-Down & Bottom-Up & $\begin{array}{l}\text { Systemic design maps situations at multiple scales to understand the } \\
\text { individual, the collective, and how they are related. Tension is } \\
\text { mediated by encouraging all sources of potential to be exploited. Top- } \\
\text { down, bottom-up, and middle-out (Bock \& Goode, 2001) perspectives } \\
\text { on sources of organisation and disruption are recognised and } \\
\text { leveraged. }\end{array}$ \\
\hline Is & Ought & $\begin{array}{l}\text { Systemic design involves both descriptive and normative reasoning. } \\
\text { What ought to be does not directly follow from what is (Hume, 2010). } \\
\text { Tension between what is perceived and what stakeholders believe } \\
\text { ought to be the case is mediated through action taken to transform } \\
\text { the system towards a more preferable future. }\end{array}$ \\
\hline Learning & Transforming & $\begin{array}{l}\text { Systemic design actions are generative: they are intended both to } \\
\text { transform the situation for the better while continuing to learn about it. } \\
\text { Experimental action within design is at once exploratory, move } \\
\text { testing, and hypothesis testing (Schön, 1987). Tension between } \\
\text { these objectives is mediated by taking actions that align learning with } \\
\text { positive change. }\end{array}$ \\
\hline
\end{tabular}

In summary, in this section we have characterised a systemic design mindset as inquiring, open, integrative, collaborative, and centred. A systemic designer who is curious, openminded, embraces the indeterminate space between polarities, works well with others, and mindfully strives for balance will approach complex challenges with both courage and humility. They will seek out difference to create, mediate, and resolve tensions between perspectives, goals, and constraints. They will be able to add to a collective understanding of 
a situation that is too complex to be fully understood from a single perspective. They will contribute to the capacity of the team to continue to adapt to a changing environment.

\section{Systemic Design Methodology}

A systemic design mindset is enacted in practice through the application of methods and methodology. Whereas a method is applied by specific users in a particular situation, methodology is an abstract logic that encompasses an entire class of systemic design applications. Methodology guides the application of a coherent sequence of methods from project initiation through to completion.

The methodology presented here has its origins in Shimon Naveh's theory of systemic operational design (Naveh et al., 2009), although the terminology has been modified as a result of reflective practice in other settings. The methodology is composed of six main activities: inquiring, framing, formulating, generating, reflecting, and facilitating. The first four of these activities map onto the four quadrants of the continuous innovation cycle in Figure 1 above. The methodology is nonlinear and iterative in application; however there is also a logic that connects these activities into a coherent learning system.

Figure 3 below shows how these activities fit together using a rich picture.

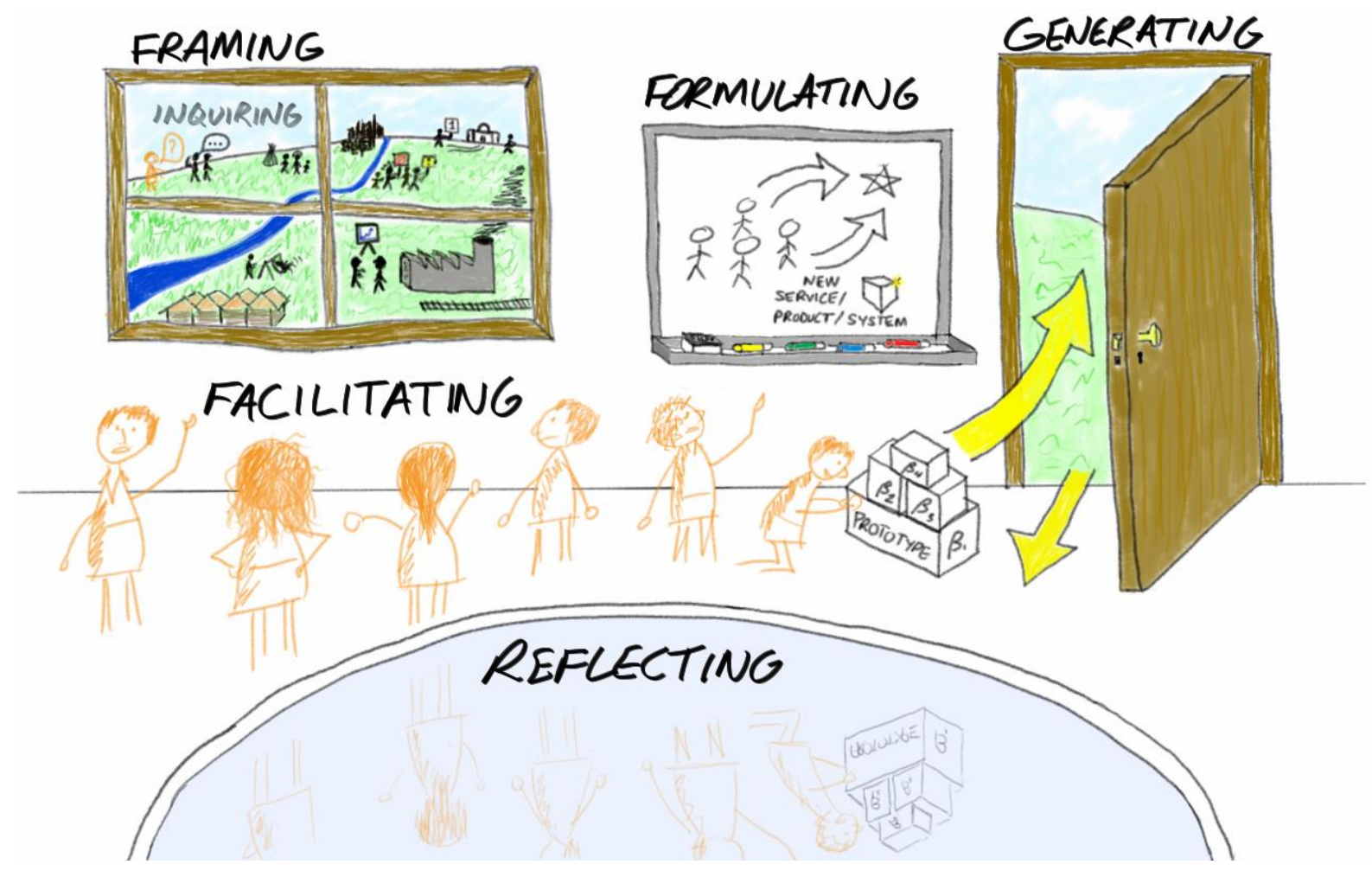

Figure 3. A rich picture of our systemic design methodology.

- Inquiring reaches outside the existing knowledge base of the team to bring external references into the design studio. This can include stakeholder ethnography, literature surveys, questioning subject matter experts, and field trips. Non-traditional data sources - art, poetry, myths, microblogging (such as Twitter) - should be examined alongside empirical data, statistical analysis, models, and peer reviewed articles. Any external reference could be relevant to the team. Relevance is judged by team members according to the potential of a reference to broaden the team's perspective, deepen the team's appreciation of the problematic situation, or expand options for 
improving it. As new questions are raised throughout the systemic design project, inquiry is ongoing and ensures the design team does not close itself off from its environment. Inquiring is not just about gathering information. Its most important role is to expose external perspectives and different world views that provide opportunities for reframing.

- Framing is "a way of selecting, organising, interpreting, and making sense of a complex reality so as to provide guideposts for knowing, analysing, persuading, and acting. A frame is a perspective from which an amorphous, ill-defined problematic situation can be made sense of and acted upon" (Schön and Rein, 1994). The goal of framing is a shared frame of reference, which is a prerequisite for shared meaning and shared understanding among a team. A shared frame can be constructed through iterative cycles of discourse about the problematic situation, mapping the problematic situation, frame reflection (Schön \& Rein, 1994), and reframing by choosing to shift the perspective for the systemic design inquiry. Participants often find this process frustrating and confusing, because they are not used to examining their own or others' frames. Yet genuine reframing is impossible until the current frame is surfaced, the inheritance of legacy frames within the current frame is acknowledged, and an alternative perspective is chosen. We frame in order to reframe - to see the same situation from a new perspective. Reframing enables us to appreciate potential to improve the situation that was not obvious from within the old frame.

- Formulating shifts the focus of designing from understanding what is, to prescribing what ought to be. David Hume (2010) first highlighted the is-ought problem in 1739: that what ought to be cannot be directly inferred from what is. Questions of what ought to be engage our values. As a normative activity, formulating should declare a reference system of values that the team seeks to enhance by acting within the situation. This should not be limited to the values of the team, but explicitly includes the values and interests of stakeholders. Based on a shared frame, the team ideates on ways to exploit potential within the situation in order to preserve and cultivate stakeholder value. Throughout the activity of formulating, the design team progressively gives form to concepts by making them tangible. Through drawing and making, the team transforms abstract concepts into concrete forms with discrete and particular extensions in space and time.

- Generating takes artifacts produced by the team and injects them into the world outside the studio. This generative act has multiple purposes. It is intended to improve the situation for stakeholders, but it is also intended to stimulate learning for the team and for stakeholders. Because the world is continually changing, and the team's understanding is imperfect, action to improve a complex situation will never produce only the intended results. The gap between expected and actual outcomes presents an opportunity to learn, even (especially) if the initial intervention appears to be a failure. This learning can be fed back into future iterations of systemic designing.

- Facilitation regulates how the team moves between each of the other activities, as well as managing the process by which each individual activity is performed. Facilitation is defined broadly to include setting and policing norms for participant behavior, selecting the number and size of sub-groups for each activity, deciding which systemic design methods to employ when and for how long, and documenting the outputs of the project. The project is documented with both visualisations and a 
narrative that tells the story of the project. The facilitation role is ongoing, and often performed by more than one team member.

- Reflecting is the touchstone for all other activities within systemic design. It is through reflection on action that teams achieve a deeper understanding of what they have done, and how what they were thinking led them to act in one particular way and not in others. Reflection enables reframing, reformulating, and learning from generative actions. Reflection differs from introspection in that reflection requires a certain distance and a foil for reflection: an external reference that through its difference enables a more critical awareness of the self. A reflective practice (Schön, 1987) is capable of self-transformation and (dis)continuous improvement, both at the level of the individual and the team. Reflection is therefore the most critical activity for systemic design to operate as a learning system.

These six activities combine in a fluid and dynamic mix to constitute a systemic design methodology. The core cycle of framing, formulating, and generating is punctuated by regular reflection, which often results in modifications of the direction and process of the design project. Inquiring and facilitating are ongoing activities, which allow the team to connect with their context and maintain internal cohesion. Together, these six activities enable a team to develop a deeper and broader appreciation of the challenge, design and inject novel artifacts and actions into the real world situation, learn from generative interactions, and feed these lessons back into future iterations of systemic design.

\section{Systemic Design Methods}

The most granular building block in our framework is the systemic design method. Systemic design methods amplify or augment natural human capacities to facilitate collaborative reasoning, visualising, modelling, and making. As tools, methods provide a set of criteria and constraints on task performance, which yields improved control both in terms of outcome and structure of the task (Baber, 2003). When systemic design projects involve co-creation with stakeholders who may be unacquainted with the principles of systems thinking or design, methods are especially useful to encourage patterns of engaging with collaborative work that may be unnatural to participants. Systemic design methods are also an important vehicle for distilling and sharing best practices among systemic design practitioners.

Systemic design often borrows methods from both systemics and design. Systemic methods we commonly employ include rich pictures (Checkland, 1981; Checkland \& Scholes, 1990), systems maps (Armson, 2011), and causal loop diagrams (Sterman, 2000). Design methods we frequently use include brainstorming (Osborn, 1948), affinity diagrams (Kawakita, 1975), and low resolution prototyping (Kelley \& Littman, 2008).

Systemic methods encourage the team to embrace complexity and model an issue from multiple perspectives and at multiple scales. They illuminate sources of emergence, selforganisation and adaptation. Systemic methods evaluate the fitness of design concepts relative to a broader context. Systemic methods avoid analytic reductionism, confining analysis to one focal scale or privileging one perspective, creating binary for/against oppositions, applying apriori universal categories, or prescribing universal standards for success.

Designerly methods are human-centred, collaborative, and synthetic. They have low barriers to entry and perform well under time pressure, while also encouraging participants to explore, diverge, and engage playfully with new possibilities. Designerly methods make thinking tangible, often by visualising or prototyping in two, three, or four dimensions. Methods that are overly technical, require specialised knowledge to learn, and months or years to apply should be avoided in co-design phases $^{2}$ of a systemic design project. Rigid and 
highly technical methods can have an intimidating effect on stakeholders, marginalising or excluding them from the conversation.

Figure 4 below illustrates the four possible classes of methods: systemic, designerly, systemic and designerly, and neither systemic nor designerly. For example, genetic algorithms (Holland, 1975) are common in systems thinking but rarely used in design thinking because they require knowledge of specialised programming skills. Video ethnography (Kumar, 2013) is accepted in design thinking, but seldom seen in systems thinking because it produces data from a single perspective. Work breakdown structures (Haugan, 2002) are neither systemic nor designerly, since they are both reductionist and quite rigid. Even methods that are not systemic or designerly may be used in systemic design, since it is the project as a whole that should be systemic and designerly. However, using methods that are consonant with both fields reinforces the systemic design mindset at the most granular level of activity, and can lead to a tighter integration of systemics and design.

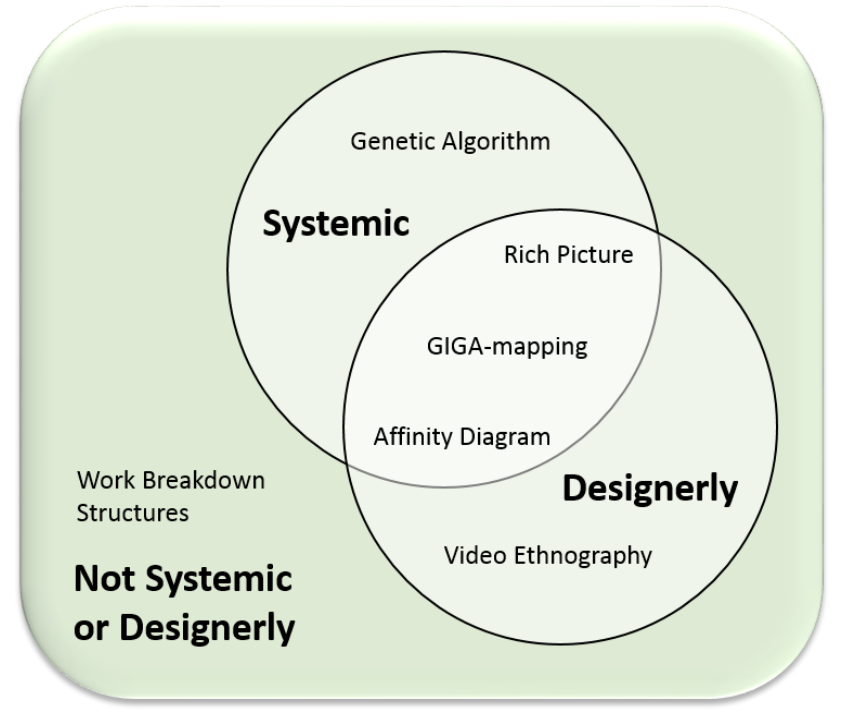

Figure 4. Venn diagram of systemic and designerly methods.

GIGA-mapping provides an example of a method that is both systemic and designerly. GIGAmapping creates an information cloud for visualising complexity from which a designer can derive innovative solutions (Sevaldson, 2011). GIGA-maps provide a multi-scale, multilayered framework for visualising information gathered during a systemic design inquiry. The GIGA-map helps to draw system boundaries, as well as to show and name connections and potential interactions across domains and categories. GIGA-maps are synthetic and flexible, potentially combining process, structure, function, imagery, hierarchical and non-hierarchical maps into a single thick description of a societal level challenge, the proposed actions to improve the situation, and potential future systemic effects.

A caution must be raised on the dangers of method, especially the more prescriptive methods sometimes borrowed from so-called "first-generation" systems thinking or design thinking. ${ }^{3}$ An over-reliance on methods can undermine the whole point of doing systemic design. Systemic design is intended to help teams to see a complex challenge in a different way, and to translate this "new seeing" into novel interventions. Taken to its extreme, the methods movement ${ }^{4}$ reduces all reasoning to a sequence of highly constrained procedures. If we apply the same procedures in the same order to each new challenge we face, we should not expect to deliver either new seeing or disruptive innovation. This is why the mindset is such a critical complement to methods and methodology. Any systemic design inquiry must maintain enough unstructured space for exploration, iteration, and divergence for surprises to emerge 
and be exploited. In our practice, a systemic design mindset encourages a fast and loose approach to the application of design method. Misuse of a method in a context it was not intended for can lead to exaptation: the team may generate a relevant new insight even though they did not strictly follow the method's guidelines or apply it to the situation it was intended for.

In summary, methods augment the capacity of teams to visualise, model, and create together during systemic design. Methods that are both systemic and designerly reinforce the mindset that is an essential part of our systemic design framework. In turn, the mindset encourages groups to apply methods loosely and playfully, to encourage emergence and avoid a mechanistic proceduralisation of systemic design.

\section{Conclusion}

Systemic design is intended for challenges characterised by complexity, uniqueness, value conflict, and ambiguity over objectives. Systemic design allows diverse teams to develop an elevated perspective of the challenge and translate novel insights into rapid action. In our proposed framework for systemic design, action taken to improve the situation also accelerates organisational learning through an iterative cycle of framing, formulating, generating, reflecting, inquiring, and facilitating. This systemic design methodology is supported by a suite of systemic design methods and enacted by diverse teams that share a systemic design mindset. The mindset is inquiring, open, integrative, collaborative, and centred. Centred systemic design mediates creative tensions and regulates both the temperature of the systemic design discourse and the tempo of inquiry for action. Together, the mindset, methodology, and methods for systemic design described in this paper provide a flexible and practical framework for integrating systems thinking and design thinking to help organisations and societies meaningfully confront their most complex challenges.

\section{Dr. Alex J. Ryan}

Senior Systems Design Manager

Government of Alberta, Department of Energy

Email address: alex.ryan@gmail.com 


\section{References}

Andrews, B. R. (1908). Habit. American Journal of Psychology, 14 (2), 121-149.

Archer, L. B. (1965). Systematic Method for Designers. London: The Design Council.

Armson, R. (2011). Growing wings on the way: Systems thinking for messy situations. Axminster, UK: Triarchy Press.

Baber, C. (2003). Cognition and Tool Use: Forms of Engagement in Human and Animal Use of Tools. London: Taylor \& Francis.

Basadur, M., Graen, G., \& Wakabayashi, M. (1990). Identifying Individual Differences In Creative Problem Solving Style. The Journal of Creative Behavior, 24 (2), 111-131.

Bock, G., \& Goode, J. (2001). Symposium on Complexity in Biological Information Processing. Complexity in biological information processing. Chichester: John Wiley, 150.

Boland, R., \& Collopy, F. (2004). Managing as designing. Stanford, CA: Stanford Business Books.

Brown, T., \& Kātz, B. (2009). Change by design: How design thinking transforms organizations and inspires innovation. New York: Harper Business.

Casti, J. L. (1997). Would-be worlds: How simulation is changing the frontiers of science. New York: J. Wiley.

Checkland, P. B. (1981). Systems thinking, systems practice. Chichester: John Wiley.

Checkland, P. B. (2000). Soft systems methodology: A thirty year retrospective. Systems Research and Behavioral Science . Retrieved February 2, 2014, from http://teaching.fec.anu.edu.au/INFS8005/R101.pdf.

Checkland, P.B., \& Scholes, J. (1990). Soft systems methodology in action. Chichester: John Wiley.

Cross, N. (2006). Forty Years of Design Research. Design Research Quarterly, 1 (2), 3-5.

Deleuze, G., \& Guattari, F. (2009). A thousand plateaus: Rhizomes. Berkeley, CA: Venus Pencils.

François, C. (1999). Systemics and cybernetics in a historical perspective. Systems Research and Behavioral Science, 16, 203-219.

Haugan, G. T. (2002). Effective work breakdown structures. Tysons Corner, VA: Management Concepts Inc.

Holland, J. H. (1975). Adaptation in natural and artificial systems: An introductory analysis with applications to biology, control and artificial intelligence. Ann Arbor: University of Michigan Press.

Hume, D., Norton, D. F., \& Norton, M. J. (2010). A treatise of human nature. Oxford: Oxford University Press.

Jackson, M. C. (2000). Systems approaches to management. New York: Kluwer Academic/Plenum.

Jones, J. C. (1969). The State-of-the-Art in Design Methods. In G. Broadbent \& A. Ward (Eds.), Design Methods in Architecture. London: Lund Humphries.

Jones, J. C. (1970). Design methods: Seeds of human futures. London: Wiley-Interscience.

Kawakita, J. (1975). KJ Method: a Scientific Approach to Problem Solving. Kawakita Research Institute.

Kelley, T., \& Littman, J. (2008). The ten faces of innovation: IDEO's strategies for beating the devil's advocate \& driving creativity throughout your organization. London: Profile.

Korzybski, A. (1933). A non-Aristotelian system and its necessity for rigour in mathematics and physics. Science and Sanity: An introduction to non-Aristotelian systems and general semantics. New York: Science Press Printing Co., 747-61.

Kumar, V. (2013). 101 design methods: A structured approach for driving innovation in your organization. Hoboken, NJ: Wiley.

Martin, R. L. (2009). The design of business: Why design thinking is the next competitive advantage. Boston, MA: Harvard Business Press.

Mau, B. (1998). An Incomplete Manifesto for Growth. Retrieved January 6, 2014, from http://www.brucemaudesign.com/4817/112450/work/incomplete-manifesto-for-growth.

Midgley, G. (Ed.). (2003). Systems thinking, Volumes 1-4. London: Sage. 
Naveh, S., Schneider, J., \& Challans, T. (2009). The Structure of Operational Revolution: A Prolegomena. Leavenworth: Booz Allen Hamilton.

Nelson, H. (2012, October). Systemics, the Logic of Design. Presentation at the First Relating Systems Thinking and Design Symposium, Oslo.

Osborn, A. F. (1948). Your creative power: how to use imagination. New York: C. Scribner's Sons.

Osborn, A. F. (1963). Applied imagination: Principles and procedures of creative problem-solving. New York: Scribner.

Rith, C., \& Dubberly, H. (2006). Why Horst WJ Rittel matters. Design Issues, 22 (4), 1-3.

Rittel, H. W., \& Webber, M. M. (1973). Dilemmas in a general theory of planning. Policy sciences, 4 (2), 155169.

Savitt, S. (2013). Being and becoming in modern physics. In E. N. Zalta (ed.), The Stanford Encyclopedia of Philosophy. Retrieved June 17, 2014, from http://www.science.uva.nl/ seop/entries/spacetimebebecome/.

Schön, D. A. (1987). Educating the Reflective Practitioner: Towards a New Design for Teaching and Learning. San Francisco, CA: Jossey-Bass.

Schön, D. A., \& Rein, M. (1994). Frame reflection: toward the resolution of intractable policy controversies. In P. Wagner, C. H. Weiss, B. Wittrock, \& H. Wollman (eds.), Social sciences and modern states: national experiences and theoretical crossroads. Cambridge: Cambridge University Press, 263.

Schwartz, S. H. (1999). A theory of cultural values and some implications for work. Applied Psychology: An International Review, 48 (1), 23-47.

Sevaldson, B. (2011). GIGA-Mapping: Visualisation for complexity and systems thinking in design. Nordes, (4).Retrieved January 15, 2014, from http://ocs.sfu.ca/nordes/index.php/nordes/2011/paper/view/409/256.

Sterman, J. (2000). Business dynamics: Systems thinking and modeling for a complex world. Boston: Irwin/McGraw-Hill.

Ulrich, W. (1983). Critical heuristics of social planning: A new approach to practical philosophy. Bern: P. Haupt.

VanPatter, G. K., \& Pastor, E. (2013). Innovation methods mapping. New York: Humantific for OPEN Innovation Consortium.

von Bertalanffy, L. (1956). General System Theory. General Systems, 1, 1-10.

Wiener, N. (1948). Cybernetics. Paris: Hermann.

\footnotetext{
${ }^{1}$ These are the type of situations that Rittel and Webber (1973) called wicked problems.

${ }^{2}$ Here we assume that the project can be divided into phases, some of which will include co-design activities with proximate team members who are not experts in systemic design.

${ }^{3}$ See (Rith \& Dubberly, 1972) for Rittel's distinction between first and second generation design methods, and Michael C. Jackson (2000) for first generation systems methods, which are contained within his chapter on functionalist systems approaches.

${ }^{4}$ By the methods movement, we mean a programme to shift practice toward a style of methods held in agreement by designers and educators in a historical cohort, which often collate and popularize representative sets of prescriptive procedures for designing, such as (Jones, 1970; Kumar, 2013).
} 